\title{
Extent of collateralization predicting symptomatic cerebral vasospasm among pediatric patients: correlations among angiography, transcranial Doppler ultrasonography, and clinical findings
}

\author{
Parham Moftakhar, MD, ${ }^{1}$ Daniel L. Cooke, MD, ${ }^{1}$ Heather J. Fullerton, MD, MAS, ${ }^{2}$ \\ Nerissa U. Ko, MD, MAS, ${ }^{2}$ Matthew R. Amans, MD, MS, ${ }^{1}$ Jared A. Narvid, MD, ${ }^{1}$ \\ Christopher F. Dowd, MD, ${ }^{1-3}$ Randall T. Higashida, MD, ${ }^{1-3}$ Van V. Halbach, MD, ${ }^{1-3}$ \\ and Steven W. Hetts, MD
}

Departments of ${ }^{1}$ Radiology and Biomedical Imaging, ${ }^{2}$ Neurology, and ${ }^{3}$ Neurological Surgery, University of California, San
Francisco, California

OBJECT Although the development and prevalence of cerebral vasospasm (CV) has been extensively investigated in adults, little data exist on the development of CV in children. The authors hypothesized that even though children have highly vasoreactive arteries, because of a robust cerebral collateral blood flow, they rarely develop symptomatic CV.

METHODS The authors retrospectively reviewed their university hospital's neurointerventional database for children (that is, patients $\leq 18$ years) who were examined or treated for aneurysmal or traumatic subarachnoid hemorrhage (SAH) during the period 1990-2013. Images from digital subtraction angiography (DSA) were analyzed for the extent of CV and collateralization of the cerebral circulation. Results from transcranial Doppler (TCD) ultrasonography were correlated with those from DSA. Cerebral vasospasm on TCD ultrasonography was defined according to criteria developed for adults. Clinical outcomes of CV were assessed with the pediatric modified Rankin Scale (mRS).

RESULTS Among 37 children (21 boys and 16 girls ranging in age from 8 months to 18 years) showing symptoms of an aneurysmal SAH (comprising 32 aneurysms and 5 traumatic pseudoaneurysms), 17 (46\%) had CV confirmed by DSA; CV was mild in $21 \%$ of these children, moderate in $50 \%$, and severe in $29 \%$. Only 3 children exhibited symptomatic CV, all of whom had poor collateralization of cerebral vessels. Among the 14 asymptomatic children, 10 (71\%) showed some degree of vessel collateralization. Among 16 children for whom TCD data were available that could be correlated with the DSA findings, $13(81 \%)$ had CV according to TCD criteria. The sensitivity and specificity of TCD ultrasonography for diagnosing CV were $95 \%$ and $59 \%$, respectively. The time to CV onset detected by TCD ultrasonography was $5 \pm 3$ days (range 2-10 days). Twenty-five (68\%) of the children had good long-term outcomes (that is, had mRS scores of 0-2).

CONCLUSIONS Children have a relatively high incidence of angiographically detectable, moderate-to-severe CV. Children rarely develop symptomatic CV and have good long-term outcomes, perhaps due to robust cerebral collateral blood flow. Criteria developed for detecting CV with TCD ultrasonography in adults overestimate the prevalence of CV in children. Larger studies are needed to define TCD ultrasonography-based CV criteria for children.

http://thejns.org/doi/abs/10.3171/2014.9.PEDS14313

KEY WORDS cerebral vasospasm; subarachnoid hemorrhage; pediatrics; vascular disorders

ABBREVIATIONS ACA = anterior cerebral artery; $C V=$ cerebral vasospasm; DSA = digital subtraction angiography; EC-ICA = extracranial-internal carotid artery; GCS = Glasgow Coma Scale; ICA = internal carotid artery; $M C A=$ middle cerebral artery; $\mathrm{mRS}=$ modified Rankin Scale, $\mathrm{PCA}=$ posterior cerebral artery; $\mathrm{PTA}=$ percutaneous angioplasty; $\mathrm{SAH}=$ subarachnoid hemorrhage; $\mathrm{TCD}=$ transcranial Doppler.

SUBMITTED June 20, 2014. ACCEPTED September 15, 2014

INCLUDE WHEN CITING Published online January 2, 2015; DOI: 10.3171/2014.9.PEDS14313.

DISCLOSURE Drs. Dowd, Cooke, and Hetts are adjudicators in the FRED Trial for Microvention, and Dr. Moftakhar received an NIH T32 training grant. 
$\mathrm{C}$ EREBRAL vasospasm (CV) continues to be a leading cause of increased morbidity and mortality rates in the setting of subarachnoid hemorrhage (SAH), especially in the young adult population..$^{20}$ Our center recently reported that among 546 adult patients admitted with an SAH almost one-half developed symptomatic CV. ${ }^{19}$ Although CV has been studied extensively in adults, there is a paucity of literature evaluating the pathophysiology and epidemiology of this condition in children.

The effect of age on CV remains controversial. Some studies have suggested that younger adults have a higher risk for developing $\mathrm{CV} .{ }^{28,29,49}$ There is no clear consensus, in part because CV can be diagnosed with different modalities and approaches, including digital subtraction angiography (DSA), CT angiography, transcranial Doppler (TCD) ultrasonography, and evaluation of clinical symptoms. The few published studies on $\mathrm{CV}$ in children have concluded that this group has a relatively high rate of $\mathrm{CV}$ diagnosed by angiography. ${ }^{11,16,33,37,39,40}$ For example, Ostergaard and Voldby ${ }^{37}$ reported a $53 \%$ rate of $\mathrm{CV}$ diagnosed on angiographic images in a pediatric cohort. Our own clinical observations and the results of the aforementioned studies suggest that, despite showing a high rate of $\mathrm{CV}$ on angiographic images, children tend not to develop symptoms referable to $\mathrm{CV}$.

In this study, we present our experience with $\mathrm{CV}$ in a pediatric cohort in the setting of both aneurysmal and traumatic SAHs. We hypothesized that even though children have a high rate of angiographic $\mathrm{CV}$, they rarely develop clinically evident symptoms of $\mathrm{CV}$, partly because individuals in this age group have a robust cerebral collateral blood flow.

\section{Methods \\ Patients}

With a protocol approved by our internal review board, we performed a retrospective review of our tertiary care hospital's neurointerventional radiology database and medical records (University of California San Francisco Medical Center and Benioff Children's Hospital). Among 90 children (age $\leq 18$ years) presenting with symptoms of intracranial aneurysms or pseudoaneurysms during the period 1990-2013, we identified 37 children who showed symptoms of SAH confirmed by a nonenhanced head CT or by lumbar puncture and for whom interpretable angiograms were available. The medical records of these children were reviewed and data were retrieved for the following variables: patient age and sex; date of symptom onset; Hunt and Hess grade, ${ }^{17}$ Fisher grade; ${ }^{7}$ location, type, and complications of aneurysms; onset, duration, distribution, and severity of CV; and pediatric modified Rankin Scale (mRS) scores $^{38}$ at the last follow-up.

\section{Initial Patient Management}

All patients were admitted to the pediatric neurointensive care unit where they received standard SAH management, modified for a pediatric population, including administration of oral nimodipine. Conventional 4-vessel DSA was performed to confirm the presence of an aneurysm and to serve as a baseline. Ruptured aneurysms were secured by surgical clipping or endovascular coil embolization. ${ }^{13}$ Frequent neurological examinations were performed, and, when available, serial TCD ultrasonograms were obtained. Patients were prophylactically placed on hypervolemic therapy when they were thought to be at risk for $\mathrm{CV}$. If patients developed new neurological deficits not explained by other causes (such as recurring hemorrhage, hydrocephalus, seizures, infection, or metabolic disturbances) and the aneurysm was secured, they were treated with pressor drugs with a goal of high normotension to mild hypertension adjusted for age; drug doses were titrated to levels resulting in an effect on the neurological deficits. Patients with rising TCD velocities suggesting worsening vasospasm were similarly placed on pressor drugs even if they had not yet developed focal neurological deficits. Those who showed persistent, worsening, or recurrent neurological deficits or increasing TCD velocities and Lindegaard ratios after 12-24 hours of treatment were considered medically refractory and were taken to the neuroangiography suite for further examination.

\section{Endovascular Treatment}

Initial DSA was performed to confirm the presence of an angiographic $\mathrm{CV}$ and to identify the vessel affected. The supraclinoid internal carotid artery (ICA), $\mathrm{M}_{1}$ segment of the middle cerebral artery (MCA), $\mathrm{A}_{1}$ segment of the anterior cerebral artery (ACA), intracranial vertebral artery, basilar artery, and $\mathrm{P}_{1}$ segment of the posterior cerebral artery (PCA) were considered proximal vessels. Those beyond the above classification (for example, $\mathbf{M}_{2}$, $\mathrm{A}_{2}$, and $\mathrm{P}_{2}$ segments) were considered distal vessels in the sense that catheterization and percutaneous angioplasty (PTA) of these smaller vessels would likely result in an unacceptable risk for vessel rupture, given their small size at baseline. For all arterial segments of the circle of Willis, the DSA images were compared with those of the pre-vasospasm baseline DSA images (if available) to avoid PTA of hypoplastic arterial segments.

The severity of $\mathrm{CV}$ was determined by experienced interventional neuroradiology attending physicians (C.F.D., V.V.H., R.T.H., and S.W.H.) who visually assessed the luminal narrowing relative to the widths of adjacent vessels in comparison with the baseline DSA. Mild CV was defined as $<30 \%$ luminal narrowing, moderate $\mathrm{CV}$ as between $30 \%$ and $50 \%$ luminal narrowing, and severe CV as $>50 \%$ luminal narrowing. Patients were treated with PTA, intraarterial verapamil infusion, or both at the discretion of the interventional neuroradiology attending physician according to our institutional standard of practice. ${ }^{19}$ Generally, severe proximal CV was treated with PTA, and distal CV was treated with verapamil.

Percutaneous angioplasty was performed as previously described. ${ }^{14}$ For systemic anticoagulation, patients undergoing a PTA received intravenous heparin injections delivering a weight-based bolus dose (typically 70 units/ $\mathrm{kg}$ ) with a goal of doubling the baseline-activated clotting time. A guiding catheter was placed on a heparinized saline drip in either the cervical ICA or the cervical vertebral artery. Next, a low-compliance tip-occlusion balloon microcatheter (Sentry-10, Boston Scientific or HyperGlide, Covidien) was navigated over a compatible 
0.0254-cm microwire to the most distal aspect of the spastic vessel segment to be treated (that is, the smallest spastic arterial branch farthest from the femoral access site). Brief $(<30 \mathrm{sec})$ and repeated balloon inflation-deflation cycles $(\leq 5)$ with iodinated contrast material were performed to achieve at least $70 \%$ of the expected baseline vascular luminal diameter. The PTA catheter was then withdrawn proximally by $50 \%$ of the balloon length (for example, a 5 -mm pull back for a 10 -mm-long balloon), and this process was repeated as necessary to cover all of the spastic arterial segments. The effect of heparinization was typically not reversed at the conclusion of the procedure.

Intraarterial verapamil infusions were performed by positioning the diagnostic catheter (4F Berenstein III or 5F UCSF2, Codman Neurovascular) in the proximal cervical ICA, the distal common carotid artery (if vascular tortuosity precluded safe ICA catheterization), or in the cervical vertebral artery proximal to the spastic vessel segment (for example, the ipsilateral ICA for treatment of distal vasospasm in the MCA or ACA). Verapamil was diluted in normal saline to a final concentration of $0.5 \mathrm{mg} / \mathrm{ml}$ and infused intraarterially at a rate of $0.5 \mathrm{mg} / \mathrm{min}$. For the few cases of isolated or particularly severe ACA or MCA vasospasm, a microcatheter (Prowler-14 LP ES, Codman Neurovascular or Excelsior SL-10, Stryker Neurovascular) over a compatible 0.0356-cm guidewire (Transend EX Platinum, Stryker Neurovascular) was navigated to the $\mathrm{A}_{1}$, $A_{2}$, or $M_{1}$ segment. Patients undergoing this microcatheterization were treated with systemic heparinization in a manner similar to that in the patients undergoing PTA, as described above. The dose of verapamil infused into each patient was determined by the catheter position and $\mathrm{CV}$ severity. Higher doses of verapamil were used in the less selective catheterizations (for example, common carotid artery catheter position versus ICA catheter position) and in more severe CV. The systemic blood pressure was maintained by titrating intravenous phenylephrine infusion during and after the intraarterial verapamil infusions.

Before 2002, we used intraarterial papaverine to treat $\mathrm{CV}$. In these cases, the microcatheter tip was placed in the supraclinoid ICA above the ophthalmic artery. The dose of intraarterial papaverine infused into each patient was determined by the catheter position and by CV severity.

In all patients, DSA was performed to assess treatment responses and complications immediately after PTA and either immediately or $\leq 30$ minutes after the verapamil infusion. Although the vasodilatory effects of PTA are seen immediately, in our experience, corroborated by animal studies ${ }^{46}$ the full vasodilatory effects of verapamil are not realized for $0.5-1$ hour after infusion. We generally minimized the time of the procedure, and thereby its risk, rather than waiting 30 minutes after the verapamil infusion to confirm the full vasodilatory effect of verapamil by angiography. In very severe cases of $\mathrm{CV}$, however, control angiograms were obtained after a 30-minute delay. Any complications were recorded.

\section{Collateralization Scoring}

To assess the extent of collateralization of the cerebral vasculature in our $\mathrm{CV}$ patients, we adapted a scoring system that has been established for ischemic stroke (Table $1) .^{5}$

\section{Transcranial Doppler Ultrasonography}

Transcranial Doppler ultrasonography was performed at the bedside by experienced sonographers using a 2-MHz pulsed probe and a commercially available TCD ultrasonography unit (Neuroguard Ultrasonographic System, Medasonics). Vessels were insonated using the method previously described by Aaslid and colleagues ${ }^{1,2}$ and included the ICA bifurcations, ACA, MCA, PCA, and vertebral and basilar arteries, as well as the external carotid arteries. Mean flow velocities were recorded in 2-mm increments along the length of each vessel. The maximum mean flow velocity was also recorded. If CV was identified, children underwent daily TCD from the day of onset until the CV had resolved.

Cerebral vasospasm was diagnosed according to criteria used in adults. Specifically, Aaslid and colleagues found that adult patients with vasospasm visible on DSA images had blood flow velocities in the MCA greater than $120 \mathrm{~cm} / \mathrm{sec}$ and blood flow velocities in the basilar artery of greater than $90 \mathrm{~cm} / \mathrm{sec}$ on TCD. ${ }^{1,2}$ Subsequently, Lindegaard et al. developed a ratio of flow velocity in the MCA to the flow velocity in the extracranial internal carotid artery (EC-ICA) to help differentiate hyperemia from $\mathrm{CV} .{ }^{25}$ Under the assumption that increased flow velocity in the EC-ICA is due to increased blood flow rather than $\mathrm{CV}$, an MCA/EC-ICA ratio $<3$ represents hyperemia. An MCA/ EC-ICA ratio $>3$ is diagnostic of CV. In our study, the criteria for the presence of $\mathrm{CV}$ included flow velocity in the MCA $>120 \mathrm{~cm} / \mathrm{sec}$, a Lindegaard ratio $>3$, and a flow velocity in the basilar artery $>90 \mathrm{~cm} / \mathrm{sec}$. Cerebral vasospasm in the other vascular territories was defined as a flow velocity $>120 \mathrm{~cm} / \mathrm{sec}$. We chose this cutoff point because it is commonly used in the literature when examining the association with angiographic vasospasm. ${ }^{8}$

\section{Patient Outcome}

The outcomes in patients were retrospectively deter-

TABLE 1. A DSA-based scale for scoring cerebral vascular collateralization in pediatric patients*

\begin{tabular}{cl}
\hline Score & \multicolumn{1}{c}{ Description } \\
\hline 1 & Collaterals reconstitute distal portion of the narrowed arterial segment \\
\hline 2 & Collaterals reconstitute proximal portion of segment adjacent to narrowed segment \\
\hline 3 & Collaterals reconstitute distal portion of segment adjacent to narrowed segment \\
\hline 5 & Collaterals reconstitute 2 segments distal to narrowed segment \\
\hline
\end{tabular}

* Based on the classification described in Christoforidis et al. 
mined by reviewing the last follow-up examination completed by a stroke neurologist, neurosurgeon, or interventional neuroradiologist and by assigning a pediatric $\mathrm{mRS}$ score. ${ }^{12,13,42}$ A functional outcome was considered good when the patient could perform the activities of daily living independently (assessed as an mRS score $\leq 2$ ), while the outcome was considered poor when the patient required assistance (mRS Score 3-5) or had died (mRS Score 6). Any causes of death were recorded.

\section{Statistical Analysis}

Means, medians, and standard deviations of ordinal variables were calculated using Excel for Mac 2008. Sensitivity and specificity were calculated using Medcalc version 13.0.2. (Microsoft Partner).

\section{Results \\ Demographics}

The 37 children ( 21 boys and 16 girls) identified by the survey in the present study ranged in age from 8 months to 18 years (mean $11.8 \pm 5$ years, median 13 years) and showed signs and symptoms of an SAH (32 aneurysmal SAHs and 5 traumatic pseudoaneurysms). The most common symptom was a sudden onset of severe headache, reported by 26 patients (70.2\%) (Table 2). The most common sign was meningismus, which was present in 7 children (18.9\%). Among those with an aneurysmal SAH, 28 children $(87.5 \%)$ had a good preoperative clinical grade (that is, a Hunt and Hess grade of I-III), and 4 (12.5\%) had a poor preoperative clinical grade (Hunt and Hess Grade $\mathrm{V})$. All but 1 child with a traumatic SAH were in moderate to severe condition at presentation (2 patients with Glasgow Coma Scale [GCS] scores of 3-8, 2 with GCS scores of 9-13, and 1 with GCS scores of 14-15).

Fifteen $(41 \%)$ of the children in this cohort had comorbidities that could have predisposed them to vascular diseases such as aneurysms. There were 51 aneurysms in 32 children, with 6 of these children having multiple aneurysms. Aneurysms of the ICA bifurcation were the most common (19.6\%) followed by $\mathrm{M}_{1}$ segment aneurysms (15.7\%) (Table 3). Time to treatment (with surgical clipping, coil embolization, or both) was $2.3 \pm 1$ days.

\section{Angiographic Results}

Twenty-eight angiograms taken in $17(46 \%)$ of the children ( 8 boys and 9 girls) showed CV. Of these 28 instances of CV, 6 (21\%) were mild, 14 (50\%) were moderate, and 8 (29\%) were severe. A combined total of 79 vessels were affected by CV; 30 vessels (38\%) had mild CV, 30 (38\%) moderate CV, and 19 (24\%) severe CV. Most cases of CV involved proximal vessels, with the supraclinoid ICA being most commonly affected (32\%). Two-thirds of CV events were observed in the anterior circulation and onethird in the posterior circulation (Table 4). All 5 cases of traumatic SAH showed CV on angiograms.

Symptomatic CV was identified in only $3(17.6 \%)$ of the 17 children, 2 of whom had a traumatic SAH. All 3 symptomatic cases showed poor collateralization of their vessels (that is, a collateral score of 5). Of the 14 asymptomatic children, 10 (71\%) had CV involving some degree
TABLE 2. Clinical characteristics of the patients in this study

\begin{tabular}{|c|c|}
\hline Score/Symptom & No. of Patients (\%) \\
\hline \multicolumn{2}{|l|}{$\mathrm{H} \& \mathrm{H}$ grade for aSAH patients } \\
\hline 1 & $12(37.5)$ \\
\hline II & $10(31.2)$ \\
\hline III & $6(18.8)$ \\
\hline IV & $0(0)$ \\
\hline V & $4(12.5)$ \\
\hline \multicolumn{2}{|l|}{ GCS score for tSAH patients } \\
\hline $3-8$ & $2(40)$ \\
\hline $9-13$ & $2(40)$ \\
\hline $14-15$ & $1(20)$ \\
\hline \multicolumn{2}{|l|}{ Fisher grade } \\
\hline 1 & $6(16.2)$ \\
\hline 2 & $2(5.5)$ \\
\hline 3 & $15(40.5)$ \\
\hline 4 & $14(37.8)$ \\
\hline \multicolumn{2}{|l|}{ Presenting signs/symptoms* } \\
\hline Headache & $26(70.2)$ \\
\hline Loss of consciousness & $8(21.6)$ \\
\hline Seizures & $3(8.1)$ \\
\hline Photophobia & $2(5.4)$ \\
\hline Meningismus & $7(18.9)$ \\
\hline Cranial nerve deficits & $3(8.1)$ \\
\hline Limb weakness & $4(10.8)$ \\
\hline Visual field defects & $3(8.1)$ \\
\hline Fever & $4(10.8)$ \\
\hline Developed hydrocephalus & $17(46.0)$ \\
\hline \multicolumn{2}{|l|}{ Comorbidities } \\
\hline Down syndrome & $3(8.1)$ \\
\hline Growth hormone deficiency & $2(5.4)$ \\
\hline Dwarfism & $2(5.4)$ \\
\hline Marfan syndrome & $1(2.7)$ \\
\hline Fibromuscular dysplasia & $1(2.7)$ \\
\hline Moyamoya disease & $1(2.7)$ \\
\hline HIV infection & $1(2.7)$ \\
\hline Polycystic kidney disease & $1(2.7)$ \\
\hline Sickle cell disease & $1(2.7)$ \\
\hline Goldenhar syndrome & $1(2.7)$ \\
\hline Nonsyndromic developmental delay & $1(2.7)$ \\
\hline
\end{tabular}

aSAH = aneurysmal SAH; $\mathrm{H} \& \mathrm{H}=\mathrm{Hunt}$ and Hess; $\mathrm{tSAH}=$ traumatic SAH.

* The total percentage exceeds $100 \%$ in this category because some patients reported or showed more than 1 symptom.

of collateralization (indicated by collateralization scores of 1-4) (Table 5) (Figs. 1-3).

Of the 17 children with CV, 9 (53\%) underwent endovascular therapies; 5 were treated with intraarterial verapamil, 1 with PTA, 2 with both intraarterial verapamil and PTA, and 1 with both intraarterial papaverine and balloon angioplasty.

Of the 37 children with SAH, 14 (38\%) showed evidence of brain infarctions on head CT scans or MRI scans obtained during their inpatient stay. Three of these cases 
TABLE 3. Number and location of aneurysms

\begin{tabular}{|c|c|}
\hline Aneurysm Site & No. of Aneurysms (\%) \\
\hline \multicolumn{2}{|l|}{ ICA } \\
\hline Supraclinoid segment & $3(5.9)$ \\
\hline Anterior choroidal & $2(3.9)$ \\
\hline Ophthalmic & $1(2.0)$ \\
\hline Bifurcation & $10(19.6)$ \\
\hline \multicolumn{2}{|l|}{ MCA } \\
\hline$M_{1}$ & $8(15.7)$ \\
\hline $\mathrm{M}_{2}$ & $1(2.0)$ \\
\hline $\mathrm{M}_{1} / \mathrm{M}_{2}$ & $3(5.9)$ \\
\hline \multicolumn{2}{|l|}{ ACA } \\
\hline$A_{1}$ & $1(2.0)$ \\
\hline $\mathrm{A}_{2}$ & $1(2.0)$ \\
\hline$A_{1} / A_{2}$ & $3(5.9)$ \\
\hline Pericallosal & $1(2.0)$ \\
\hline Basilar & $4(7.8)$ \\
\hline \multicolumn{2}{|l|}{ PCA } \\
\hline$P_{1}$ & $3(5.9)$ \\
\hline $\mathrm{P}_{2}$ & $1(2.0)$ \\
\hline$P_{1} / P_{2}$ & $2(3.9)$ \\
\hline PCoA & $4(7.8)$ \\
\hline SCA & $3(5.9)$ \\
\hline
\end{tabular}

$\mathrm{PCOA}=$ posterior communicating artery; $\mathrm{SCA}=$ superior cerebellar artery.

were potentially related to procedural complications (2 clipping-related infarctions and 1 coil embolization-related infarction), and the remaining 11 were related to $\mathrm{CV}$. Eight of these 11 cases showed small infarctions with no clinical consequence. The remaining 3 patients with infarctions were those who showed symptoms of CV and whose intracranial vasculature had a collateralization score of 5. Nine patients had complications due to infection (3 mycotic aneurysms, 2 ventriculitis, 3 respiratory infections, and 1 sepsis).

\section{Correlation of DSA Data With TCD Data}

For 16 children-only 1 of whom had symptomatic

TABLE 4. Location and severity of $\mathrm{CV}^{*}$

\begin{tabular}{crrrr}
\hline & \multicolumn{3}{c}{ Degree of Vasospasm } & \\
\cline { 2 - 4 } Vessel/Segment & Mild & Moderate & Severe & Total \\
\hline ICA & 11 & 6 & 8 & 25 \\
\hline VA & 1 & 1 & 2 & 4 \\
\hline$A_{1}$ & 5 & 3 & 2 & 10 \\
\hline$A_{2}$ & 2 & 1 & 0 & 3 \\
\hline$M_{1}$ & 6 & 7 & 6 & 19 \\
\hline$M_{2}$ & 0 & 1 & 1 & 2 \\
\hline BA & 2 & 7 & 0 & 9 \\
\hline$P_{1}$ & 3 & 4 & 0 & 7 \\
\hline Total & 30 & 30 & 19 & 79 \\
\hline$B A$
\end{tabular}

$\mathrm{BA}=$ basilar artery; $\mathrm{VA}=$ vertebral artery.

* The values in this table indicate the number of vessel segments with CV.
TABLE 5. Association between the extent of collateralization and CV

\begin{tabular}{cccc}
\hline & \multicolumn{3}{c}{ No. of Patients (\%) } \\
\cline { 2 - 4 } Collateral Score & Total & $\begin{array}{c}\text { Symptomatic } \\
\text { for CV }\end{array}$ & $\begin{array}{c}\text { Asymptomatic } \\
\text { for CV }\end{array}$ \\
\hline 1 & $5(29.4)$ & $0(0)$ & $5(35.7)$ \\
\hline 2 & $1(5.9)$ & $0(0)$ & $1(7.1)$ \\
\hline 3 & $2(11.8)$ & $0(0)$ & $2(14.3)$ \\
\hline 4 & $2(11.8)$ & $0(0)$ & $2(14.3)$ \\
\hline 5 & $7(41.2)$ & $3(100)$ & $4(28.6)$ \\
\hline
\end{tabular}

CV-TCD data were available that could be correlated with data from DSA performed on the same day. Thirteen $(81 \%)$ of these children showed symptoms of CV according to the criteria used for analysis of TCD data from adults. Among these 13 children, a total of 33 vessels showed CV according to these TCD criteria. However, for 12 children, the results of the TCD and DSA examinations disagreed. Specifically, in $18(55 \%)$ of the vessels, CV was diagnosed by TCD ultrasonography, but no evidence of CV was observed with DSA (Table 6). The average maximum mean flow velocity in these patients was $142.6 \mathrm{~cm} /$ sec (range 124-166 cm/sec). The overall sensitivity and specificity of TCD ultrasonography for $\mathrm{CV}$ detection were $95 \%$ and $59 \%$, respectively (Table 6).

The time to $\mathrm{CV}$ onset after an SAH was $5 \pm 3$ days (range 2-10 days, median 4 days) as measured by TCD ultrasonography; the time to $\mathrm{CV}$ onset as determined by DSA was $7 \pm 5$ days (range $2-23$ days, median 5 days). CV persisted for an average of $7.5 \pm 3$ days (range 3-17 days, median 7 days).

\section{Outcomes}

Twenty-five children (68\%) had good outcomes (that is, had mRS scores of 0-2) over an average follow-up period of 19.7 months (median 12.0 months). All 3 children who experienced symptomatic CV also had good long-term outcomes over an average follow-up period of 19.7 months.

\section{Discussion}

To our knowledge, this is the first study demonstrating a relationship between cerebral arterial collateralization and tolerance to $\mathrm{CV}$ in children. Furthermore, this is the first study to attempt to correlate TCD findings with those from DSA in children with CV. Given the paucity of information in the literature on CV in children, we believe our findings will help elucidate the pathophysiology of this disease process in this age group and aid in developing strategies for managing $\mathrm{CV}$ in children and young adults.

Although the incidence of symptomatic CV is low in children, the observations in our study indicate that the prevalence of $\mathrm{CV}$ determined by angiography is relatively high (that is, 46\%). Our findings are consistent with those from a few other studies. ${ }^{11,16,33,37,39,40}$ Saraf et al. ${ }^{43}$ recently reported a 57\% rate of angiographic CV in 14 children with ruptured brain aneurysms. This relatively high rate of angiographic $\mathrm{CV}$ is likely due to the high vasoreactivity of 


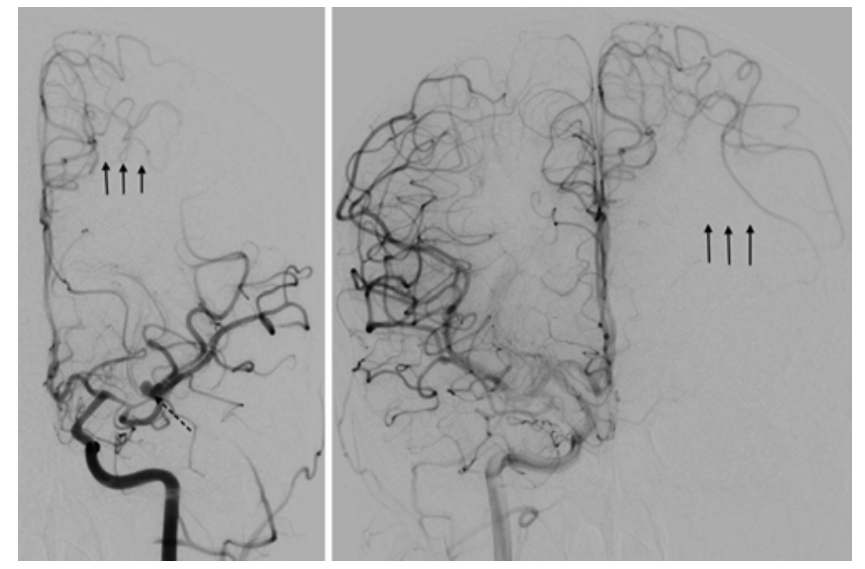

FIG. 1. Shifting watershed pial collateral vessels. Left: ICA angiogram in a 16-year-old patient with a ruptured mycotic MCA bifurcation aneurysm (dotted arrow) with adjacent CV of the MCA and collateral vessels from the distal ACA to the distal MCA (arrows). Right: ICA angiogram in the same patient with watershed collaterals from the ACA (arrows).

the vessels in young individuals. In contrast, as explained by Magge et al., ${ }^{29}$ the increased stiffness of the cerebral vasculature associated with advanced age may explain the lower prevalence of angiographic CV in the population of older adults. Postmortem studies in humans have indicated that aging leads to an increased accumulation of collagen in the vessel wall, along with intimal thickening and fibrosis. ${ }^{10,15}$ These changes and the accumulation of atherosclerotic plaque decrease vessel distensibility. Vessel reactivity to mediators of vasoconstriction (such as serotonin and prostaglandins) may also decrease with age., ${ }^{918}$

Interestingly, in our study, both the prevalence and severity of angiographic CV were high in children (79\% of our cases exhibited moderate-to-severe CV). Our findings are similar to those of other studies. For example, Yoshimoto and $\mathrm{Kwak}^{49}$ and Macdonald et al., ${ }^{28}$ who used DSA to diagnose $\mathrm{CV}$, observed that a younger age is associated with a greater frequency of severe angiographic $\mathrm{CV}$. Magge et al. ${ }^{29}$ also reported that the likelihood of severe vasospasm was greater with a younger age; patients with severe angiographic CV were on average 9 years younger than those with no CV. Again, this is likely attributable to the relatively increased vasoreactivity at younger ages. Thus, the risk for vasospasm detected by angiography can be described as varying linearly with age, with younger individuals being more prone to developing $\mathrm{CV}$ than older ones.

Despite the high rate of angiographic CV in our study, only 3 children had symptomatic CV. It appears that children tolerate $\mathrm{CV}$ better than adults. Ostergaard and Voldby, ${ }^{37}$ reported a $53 \%$ rate of angiographic CV in children without an associated neurological deterioration. Proust et al., ${ }^{40}$ in a series of pediatric patients, observed that CV was always asymptomatic. Krishna et al., ${ }^{21}$ reported that the incidence of angiographic CV was $37 \%$ in adults and $41 \%$ in children. Clinically symptomatic CV, which was treated with "triple-H" therapy (that is, with interventions inducing hypertension, hemodilution, and hypervolemia), was observed in $28.4 \%$ of adults and only in $9.5 \%$ of children. Thus, appearance of symptomatic CV may follow an inverted U-shaped curve, with a lower prevalence at both

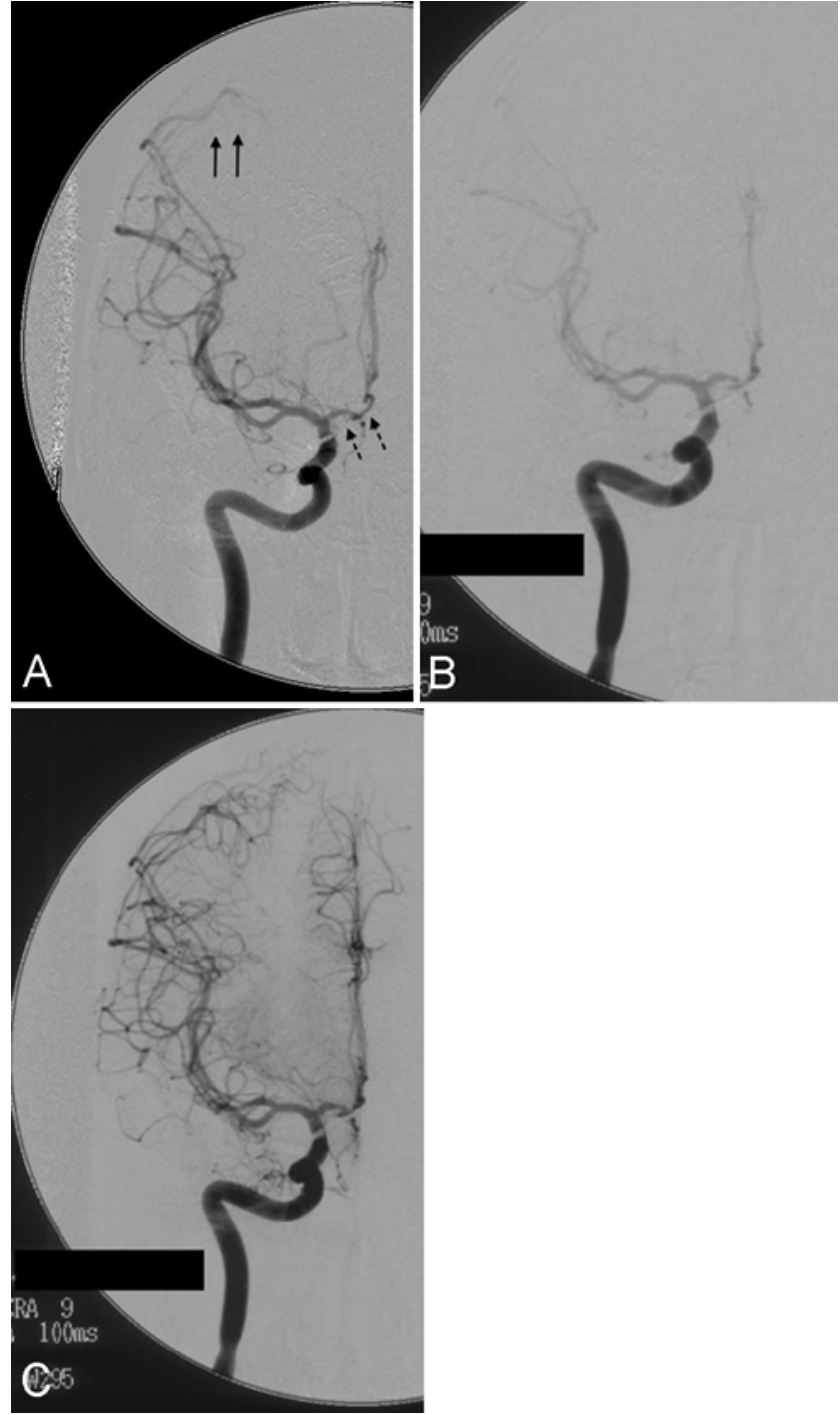

FIG. 2. Collateralization of vessels pre- and postangioplasty. A: Preangioplasty ICA midarterial angiogram in an 18-year-old patient who has a clipped ACA aneurysm exhibiting CV of the ACA (dotted arrows) with distal collateralization from the right MCA (arrows) (that is, the MCA is reaching the vertex more quickly than the ACA does on the anteroposterior view). After pharmacological (with intraarterial papaverine) and mechanical angioplasty, early arterial (B) and midarterial (C) right ICA angiograms show equalization in flow between the right $\mathrm{ACA}$ and right MCA (that is, the MCA and ACA are reaching the same vertical height on the anteroposterior angiogram).

very young and older ages and the highest prevalence in early adulthood.

That children are rarely symptomatic for CV may be due at least in part to their robust collateralization of cerebral vessels. All 3 children who showed CV symptoms had poor collateralization scores (that is, a score of 5), while $71 \%$ of the children who showed no symptoms had some degree of collateralization. That not all symptom-free children had a robust collateral flow indicates that the development of symptomatic CV is most likely multifactorial. Other biological features, such as the robustness of the nitric oxide synthase pathway in children may play a role in preventing symptomatic CV..$^{45}$ Furthermore, incipient development of 

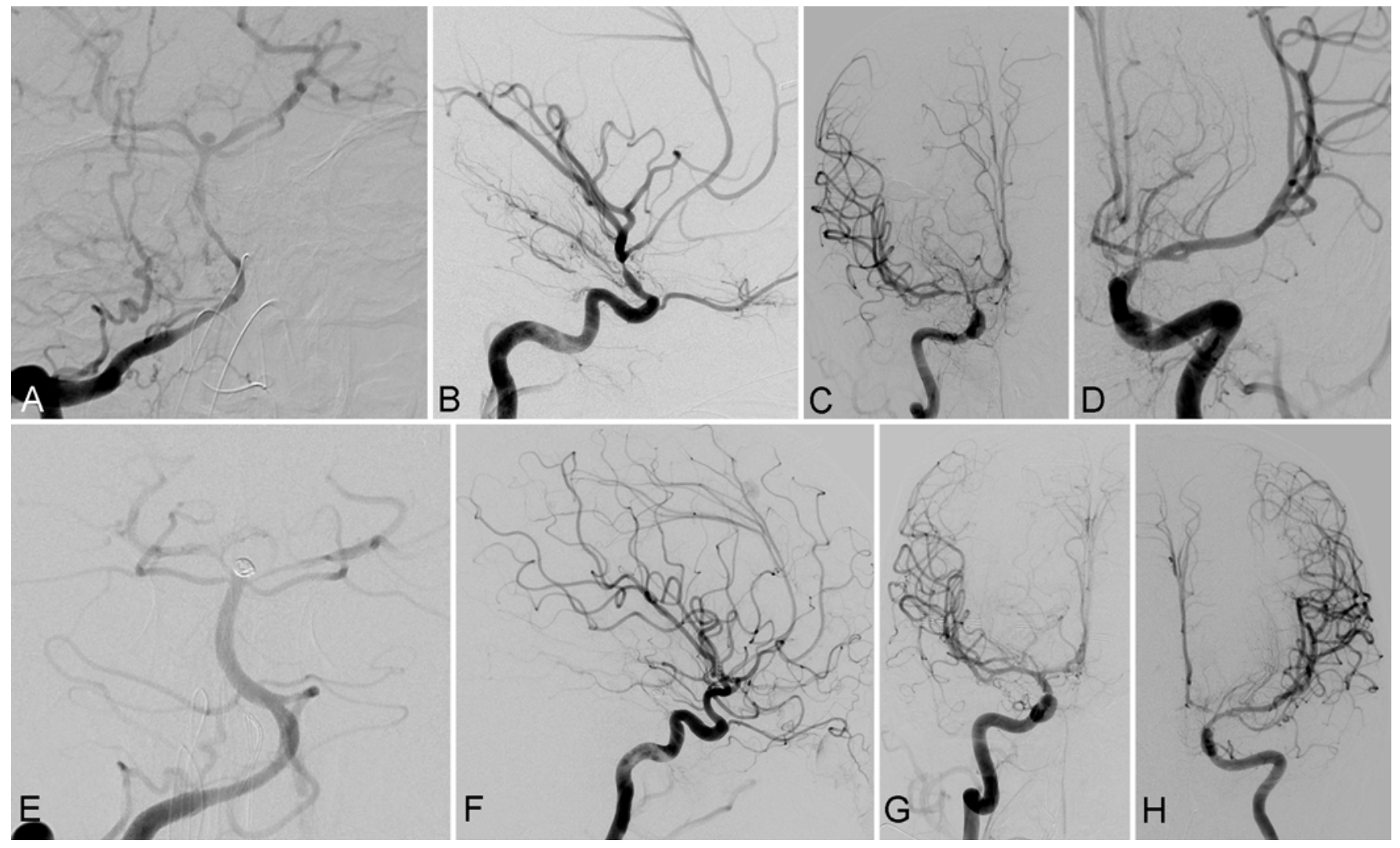

FIG. 3. Poor collateralization of circulation. A-D: Angiograms of a 12-year-old girl with a ruptured basilar tip aneurysm exhibiting diffuse, severe CV with poor collateralization (indicated by a collateral score of 5); the patient showed symptoms consistent with

CV. E-H: Postangioplasty angiograms after intraarterial verapamil infusions indicate marked improvement of CV in this patient.

collateral vessels does not guarantee that these vessels will persist. Hemodynamic fluctuations may influence the endurance of such collateral circulation. ${ }^{24}$

The good long-term outcomes among the children in our study may be due to several factors. First, children tend to have better clinical grades than adults. In the present study, $87.5 \%$ of the children had a good preoperative grade (that is, Hunt and Hess grades of I-III). The reason for the better clinical grades at presentation is unclear but may be attributable to several factors, such as few comorbidities and a greater tendency among physicians to refer cerebrovascular cases to tertiary care centers. ${ }^{31}$ Second, good long-term outcomes may be partially attributable to the low prevalence of symptomatic $\mathrm{CV}$ due to the robustness of the cerebral collateral circulation in children. However, the 3 children who experienced symptomatic $\mathrm{CV}$ also had relatively good long-term outcomes. These outcomes may be due in part to the high brain plasticity and relative lack of atherosclerosis seen in children compared with adults. Velocity of cerebral blood flow declines with age, and this decline may be associated with certain changes in cerebrovascular hemodynamics such as 1) a decreased cerebral blood flow or metabolic demands, 2) vessel-size changes, and 3) lower cardiac output. $22,26,32,34,41$

By TCD criteria, the children showed a high rate of CV (81\%), but the prevalence of symptomatic CV was low (1 child). However, in our study, the findings obtained with TCD ultrasonography differed from those obtained with

TABLE 6. Sensitivity and specificity of TCD findings in diagnosing $C V$ in comparison with DSA findings (used as the gold standard)

\begin{tabular}{lccccrr}
\hline Vessel & $\begin{array}{c}\text { True Positive } \\
(\mathrm{DSA}+\text { /TCD+) }\end{array}$ & $\begin{array}{c}\text { False Positive } \\
(\mathrm{DSA}-/ \mathrm{TCD}+)\end{array}$ & $\begin{array}{c}\text { True Negative } \\
(\mathrm{DSA}-/ \mathrm{TCD}-)\end{array}$ & $\begin{array}{r}\text { False Negative } \\
(\mathrm{DSA}+/ \mathrm{TCD}-)\end{array}$ & Sensitivity (\%) & Specificity (\%) \\
\hline MCA & 6 & 5 & 3 & 1 & 85 & 40 \\
\hline ICA & 2 & 5 & 3 & 0 & 100 & 40 \\
\hline ACA & 1 & 4 & 4 & 0 & 100 & 50 \\
\hline PCA & 1 & 0 & 4 & 0 & 100 & 100 \\
\hline BA & 4 & 4 & 2 & 1 & 80 & 33 \\
\hline VA & 1 & 0 & 2 & 0 & 100 & 100 \\
\hline Overall & 15 & 18 & 18 & 2 & 95 & 59 \\
\hline
\end{tabular}


DSA (the gold standard for CV detection) in 12 of the 13 children who had shown CV by TCD criteria. Therefore, the diagnosis of $\mathrm{CV}$ based on TCD criteria developed for adults appears to overestimate the true prevalence of $\mathrm{CV}$ in children. Of concern is that baseline flow velocities in children are higher than in adults..$^{3,44,48}$ O'Brien et al., ${ }^{35}$ examining $\mathrm{CV}$ in children after traumatic brain injuries, reported an overall $63.7 \%$ incidence of $\mathrm{CV}$ by adult TCD criteria. The authors also noted that since normal flow velocities are higher in children than in adults, the adult diagnostic criteria used in their study may have overestimated the true incidence of CV in their pediatric head trauma patients. Our study demonstrates that TCD ultrasonography has high sensitivity but low specificity in diagnosing CV. This is in contrast to what has been described in adults. Lysakowski et al., ${ }^{27}$ in a meta-analysis of 26 reports, concluded that for the MCA territory in adults, TCD ultrasonography has high specificity, but low sensitivity in the detection of CV after an aneurysmal SAH. Currently, no case-controlled studies have compared TCD flow velocity data with DSA data in pediatric patients suspected of having $\mathrm{CV}$.

In the present study, the time to onset of $\mathrm{CV}$ as determined by TCD ultrasonography was $5 \pm 3$ days, and CV persisted for an average of $7.5 \pm 3$ days. These results were comparable to those observed for adults with $\mathrm{CV}$ after an $\mathrm{SAH} .{ }^{47}$

All 5 children with a traumatic SAH had CV diagnosed with angiography. Although our sample size was small, the prevalence of $\mathrm{CV}$ observed in the present study was similar to that reported from several studies in adult patients with traumatic brain injury. $6,23,30,36$

Our study is limited by its retrospective nature. Not every child underwent a TCD examination, and not every DSA finding could be compared with one from a TCD examination. Although we present one of the largest studies to date on $\mathrm{CV}$ in children, a prospective study comparing TCD flow velocity to angiographic data would be helpful in developing more robust TCD criteria for diagnosing CV in children. Such prospective studies could improve the understanding of the true prevalence of this pathological condition and how often $\mathrm{CV}$ leads to clinically significant ischemia in children.

\section{Conclusions}

Based on DSA findings, children show a relatively high prevalence of moderate-to-severe CV. However, children rarely develop symptomatic CV and have good long-term outcomes, perhaps due in part to their robust cerebral collateral blood flow. Diagnosis of CV with TCD ultrasonography and use of diagnostic criteria developed for adults tend to overestimate the prevalence of $\mathrm{CV}$ in the pediatric population.

\section{References}

1. Aaslid R, Huber P, Nornes H: Evaluation of cerebrovascular spasm with transcranial Doppler ultrasound. J Neurosurg 60:37-41, 1984

2. Aaslid R, Markwalder TM, Nornes H: Noninvasive transcranial Doppler ultrasound recording of flow velocity in basal cerebral arteries. J Neurosurg 57:769-774, 1982
3. Bode H, Eden A: Transcranial Doppler sonography in children. J Child Neurol 4 (Suppl):S68-S76, 1989

4. Bode H, Wais U: Age dependence of flow velocities in basal cerebral arteries. Arch Dis Child 63:606-611, 1988

5. Christoforidis GA, Karakasis C, Mohammad Y, Caragine LP, Yang M, Slivka AP: Predictors of hemorrhage following intra-arterial thrombolysis for acute ischemic stroke: the role of pial collateral formation. AJNR Am J Neuroradiol 30:165-170, 2009

6. Compton JS, Teddy PJ: Cerebral arterial vasospasm following severe head injury: a transcranial Doppler study. Br J Neurosurg 1:435-439, 1987

7. Fisher CM, Kistler JP, Davis JM: Relation of cerebral vasospasm to subarachnoid hemorrhage visualized by computerized tomographic scanning. Neurosurgery 6:1-9, 1980

8. Frontera JA, Fernandez A, Schmidt JM, Claassen J, Wartenberg KE, Badjatia N, et al: Defining vasospasm after subarachnoid hemorrhage: what is the most clinically relevant definition? Stroke 40:1963-1968, 2009

9. Hamel E, Assumel-Lurdin C, Bouloy M, MacKenzie ET: Selective age-related changes in neuronal markers and smooth muscle reactivity in cerebrovascular beds of Fischer 344 rats. Neurobiol Aging 11:631-639, 1990

10. Hegedüs K, Molnár P: Age-related changes in reticulin fibers and other connective tissue elements in the intima of the major intracranial arteries. Clin Neuropathol 8:92-97, 1989

11. Heiskanen O, Vilkki J: Intracranial arterial aneurysms in children and adolescents. Acta Neurochir (Wien) 59:55-63, 1981

12. Hetts SW, Keenan K, Fullerton HJ, Young WL, English JD, Gupta N, et al: Pediatric intracranial nongalenic pial arteriovenous fistulas: clinical features, angioarchitecture, and outcomes. AJNR Am J Neuroradiol 33:1710-1719, 2012

13. Hetts SW, Narvid J, Sanai N, Lawton MT, Gupta N, Fullerton HJ, et al: Intracranial aneurysms in childhood: 27-year single-institution experience. AJNR Am J Neuroradiol 30:1315-1324, 2009

14. Higashida RT, Halbach VV, Dowd CF, Dormandy B, Bell J, Hieshima GB: Intravascular balloon dilatation therapy for intracranial arterial vasospasm: patient selection, technique, and clinical results. Neurosurg Rev 15:89-95, 1992

15. Hoh BL, Topcuoglu MA, Singhal AB, Pryor JC, Rabinov JD, Rordorf GA, et al: Effect of clipping, craniotomy, or intravascular coiling on cerebral vasospasm and patient outcome after aneurysmal subarachnoid hemorrhage. Neurosurgery 55:779-789, 2004

16. Huang J, McGirt MJ, Gailloud P, Tamargo RJ: Intracranial aneurysms in the pediatric population: case series and literature review. Surg Neurol 63:424-433, 2005

17. Hunt WE, Hess RM: Surgical risk as related to time of intervention in the repair of intracranial aneurysms. J Neurosurg 28:14-20, 1968

18. Johnson MD, Wray A: Alpha 1 adrenergic receptor function in senescent Fischer 344 rat aorta. Life Sci 46:359-366, 1990

19. Jun P, Ko NU, English JD, Dowd CF, Halbach VV, Higashida RT, et al: Endovascular treatment of medically refractory cerebral vasospasm following aneurysmal subarachnoid hemorrhage. AJNR Am J Neuroradiol 31:1911-1916, 2010

20. Kassell NF, Torner JC, Haley EC Jr, Jane JA, Adams HP, Kongable GL: The International Cooperative Study on the Timing of Aneurysm Surgery. Part 1: Overall management results. J Neurosurg 73:18-36, 1990

21. Krishna H, Wani AA, Behari S, Banerji D, Chhabra DK, Jain VK: Intracranial aneurysms in patients 18 years of age or under, are they different from aneurysms in adult population? Acta Neurochir (Wien) 147:469-476, 2005

22. Kusunoki K, Oka Y, Saito M, Sadamoto K, Sakaki S, Miki H, et al: Changes in visibility of intracranial arteries on MRA with normal ageing. Neuroradiology 41:813-819, 1999 
23. Lee JH, Martin NA, Alsina G, McArthur DL, Zaucha K, Hovda DA, et al: Hemodynamically significant cerebral vasospasm and outcome after head injury: a prospective study. $\mathbf{J}$ Neurosurg 87:221-233, 1997

24. Liebeskind DS: Collateral circulation. Stroke 34:2279-2284, 2003

25. Lindegaard KF, Nornes H, Bakke SJ, Sorteberg W, Nakstad P: Cerebral vasospasm diagnosis by means of angiography and blood velocity measurements. Acta Neurochir (Wien) 100:12-24, 1989

26. Lund-Johansen P: The hemodynamics of the aging cardiovascular system. J Cardiovasc Pharmacol 12 (Suppl 8):S20_ S32, 1988

27. Lysakowski C, Walder B, Costanza MC, Tramèr MR: Transcranial Doppler versus angiography in patients with vasospasm due to a ruptured cerebral aneurysm: a systematic review. Stroke 32:2292-2298, 2001

28. Macdonald RL, Wallace MC, Coyne TJ: The effect of surgery on the severity of vasospasm. J Neurosurg 80:433-439, 1994

29. Magge SN, Chen HI, Ramakrishna R, Cen L, Chen Z, Elliott $\mathrm{JP}$, et al: Association of a younger age with an increased risk of angiographic and symptomatic vasospasms following subarachnoid hemorrhage. J Neurosurg 112:1208-1215, 2010

30. Martin NA, Doberstein C, Zane C, Caron MJ, Thomas K, Becker DP: Posttraumatic cerebral arterial spasm: transcranial Doppler ultrasound, cerebral blood flow, and angiographic findings. J Neurosurg 77:575-583, 1992

31. Mehrotra A, Nair AP, Das KK, Srivastava A, Sahu RN, Kumar R: Clinical and radiological profiles and outcomes in pediatric patients with intracranial aneurysms. J Neurosurg Pediatr 10:340-346, 2012

32. Melamed E, Lavy S, Bentin S, Cooper G, Rinot Y: Reduction in regional cerebral blood flow during normal aging in man. Stroke 11:31-35, 1980

33. Meyer FB, Sundt TM Jr, Fode NC, Morgan MK, Forbes GS, Mellinger JF: Cerebral aneurysms in childhood and adolescence. J Neurosurg 70:420-425, 1989

34. Murphy DG, DeCarli C, McIntosh AR, Daly E, Mentis MJ, Pietrini P, et al: Sex differences in human brain morphometry and metabolism: an in vivo quantitative magnetic resonance imaging and positron emission tomography study on the effect of aging. Arch Gen Psychiatry 53:585-594, 1996

35. O'Brien NF, Reuter-Rice KE, Khanna S, Peterson BM, Quinto KB: Vasospasm in children with traumatic brain injury. Intensive Care Med 36:680-687, 2010

36. Oertel M, Boscardin WJ, Obrist WD, Glenn TC, McArthur DL, Gravori T, et al: Posttraumatic vasospasm: the epidemiology, severity, and time course of an underestimated phenomenon: a prospective study performed in 299 patients. $\mathbf{J}$ Neurosurg 103:812-824, 2005

37. Ostergaard JR, Voldby B: Intracranial arterial aneurysms in children and adolescents. J Neurosurg 58:832-837, 1983

38. Palisano R, Rosenbaum P, Walter S, Russell D, Wood E, Galuppi B: Development and reliability of a system to classify gross motor function in children with cerebral palsy. Dev Med Child Neurol 39:214-223, 1997

39. Pasqualin A, Mazza C, Cavazzani P, Scienza R, DaPian R:
Intracranial aneurysms and subarachnoid hemorrhage in children and adolescents. Childs Nerv Syst 2:185-190, 1986

40. Proust F, Toussaint P, Garniéri J, Hannequin D, Legars D, Houtteville JP, et al: Pediatric cerebral aneurysms. J Neurosurg 94:733-739, 2001

41. Safar M: Ageing and its effects on the cardiovascular system. Drugs 39 (Suppl 1):1-8, 1990

42. Sanchez-Mejia RO, Chennupati SK, Gupta N, Fullerton H, Young WL, Lawton MT: Superior outcomes in children compared with adults after microsurgical resection of brain arteriovenous malformations. J Neurosurg 105 (2 Suppl):82-87, 2006

43. Saraf R, Shrivastava M, Siddhartha W, Limaye U: Intracranial pediatric aneurysms: endovascular treatment and its outcome. J Neurosurg Pediatr 10:230-240, 2012

44. Schöning M, Staab M, Walter J, Niemann G: Transcranial color duplex sonography in childhood and adolescence. Age dependence of flow velocities and waveform parameters. Stroke 24:1305-1309, 1993

45. Siuta M, Zuckerman SL, Mocco J: Nitric oxide in cerebral vasospasm: theories, measurement, and treatment. Neurol Res Int 2013:972417, 2013

46. Takayasu M, Bassett JE, Dacey RG Jr: Effects of calcium antagonists on intracerebral penetrating arterioles in rats. $\mathbf{J}$ Neurosurg 69:104-109, 1988

47. Topcuoglu MA, Pryor JC, Ogilvy CS, Kistler JP: Cerebral vasospasm following subarachnoid hemorrhage. Curr Treat Options Cardiovasc Med 4:373-384, 2002

48. Wintermark M, Lepori D, Cotting J, Roulet E, van Melle G, Meuli R, et al: Brain perfusion in children: evolution with age assessed by quantitative perfusion computed tomography. Pediatrics 113:1642-1652, 2004

49. Yoshimoto Y, Kwak S: Age-related multifactorial causes of neurological deterioration after early surgery for aneurysmal subarachnoid hemorrhage. J Neurosurg 83:984-988, 1995

\section{Author Contributions}

Conception and design: Hetts, Moftakhar. Acquisition of data: Moftakhar. Analysis and interpretation of data: Hetts, Moftakhar. Drafting the article: Moftakhar. Critically revising the article: Hetts, Cooke, Fullerton, Ko, Dowd, Higashida, Halbach. Reviewed submitted version of manuscript: Hetts, Amans, Narvid. Study supervision: Hetts, Dowd, Higashida, Halbach.

\section{Supplemental Information}

Proceedings

Portions of this work were presented as an abstract in the proceedings of the American Society of Neuroradiology (ASNR) Annual Meeting, Montreal, Quebec, Canada, May 17-22, 2014.

\section{Correspondence}

Steven W. Hetts, Neurointerventional Radiology, 505 Parnassus Ave., L-352, San Francisco, CA 94143-0628. email: steven. hetts@radiology.ucsf.edu. 